\title{
FREQUÊNCIA DE ANTICORPOS CONTRA METAPNEUMOVÍRUS AVIÁRIO EM CRIAÇÕES INDUSTRIAIS E DE GALINHAS DE QUINTAL NO POLO AVÍCOLA DA BAHIA
}

\author{
Tatiane Santana Sales, ${ }^{1}$ Elen Fabiane Guimarães Herval, ${ }^{1}$ Priscila Sousa da Silva ${ }^{3}$ Jamille Machado de \\ Lima, ${ }^{4}$ Izabella Ramos ${ }^{5}$ e Lia Muniz Barretto Fernandes ${ }^{6}$
}

1. Mestranda da pós-graduação em Ciência Animal nos Trópicos da Escola de Medicina Veterinária da Universidade Federal da Bahia. E-mail: tatiane.santana@yahoo.com.br

2. Mestranda da pós-graduação em Ciência Animal nos Trópicos da EMEV-UFBA

3. Mestranda da pós-graduação em Ciência Animal nos Trópicos da EMEV-UFBA 4. Estudante de graduação da Escola de Medicina Veterinária da UFBA

5. Vice-coordenadora do Laboratório de Sanidade Avícola da Bahia da EMEV-UFBA

6. Professora adjunta e coordenadora do Laboratório de Sanidade Avícola da Bahia, UFBA.

\section{RESUMO}

Este estudo teve como objetivo determinar a frequência de anticorpos contra o metapneumovírus aviário (AMPV) em criações, não vacinadas, de frangos de corte e galinhas de quintal no polo avícola do Estado da Bahia. Coletaram-se 622 amostras de soro de criações de frangos de corte e 268 amostras de galinhas de quintal. A sorologia foi realizada por meio do kit comercial de ELISA indireto. $\mathrm{Na}$ análise estatística utilizou-se o teste $t$ de Student com intervalo de confiança de $95 \%$. Detectaram-se aves soropositivas para o AMPV tanto nos frangos de corte $(144 ; 23,15 \%)$ quanto nas galinhas de quintal $(187 ; 69,78 \%)(p=0,1)$. Os lotes de frangos de corte tiveram frequência de anticorpos contra o AMPV de $77,14 \%$ e as propriedades de aves caipiras de $94,12 \%$. No grupo de frangos de corte evidenciaram-se anticorpos contra o vírus em $66,67 \%$ e $33,33 \%$ das aves com e sem sintomas respiratórios, respectivamente. Já nas aves caipiras foram encontradas frequências elevadas de soropositivas tanto nas aves com sintomas respiratórios $(60,43 \%)$ quanto naquelas sem sintomas $(39,57 \%)$. Os resultados demonstram que houve infecção pelo vírus nas criações de frangos de corte e de galinhas de quintal, sugerindo a presença do AMPV no polo avícola da Bahia.

PALAVRAS-CHAVES: ELISA indireto, frangos de corte, galinhas de quintal, metapneumovírus aviário.

\section{ABSTRACT}

\section{FREQUENCY OF ANTIBODIES AGAINST AVIAN METAPNEUMOVIRUS IN CHICKEN INDUSTRIAL AND BACKYARD REARING ON BAHIA'S POULTRY POLE}

This study aimed to determine the frequency of antibodies against avian metapneumovirus (AMPV) in unvaccinated broilers and backyard chicken reared in the Poultry Production pole of Bahia, Brazil. A total of 622 and 268 serum samples of broilers and backyard chickens were collected, respectively. Serology was carried out using indirect ELISA and statistical analysis was performed using Student T, with confidence interval of $95 \%$. Seropositive poultry were detected in 144 broilers $(23.15 \%)$ and in 187 backyard chicken $(69.78 \%)$.
The frequency of antibodies against AMPV was $77.14 \%$ in flocks of broilers and $94.12 \%$ in backyard chicken. In broilers group, antibodies were observed in $66.67 \%$ and $33.33 \%$ of poultry with or without respiratory signs, respectively. In backyard chicken, high frequency of the antibody was found in both poultry with symptoms $(60.43 \%)$ and in the asymptomatic ones (39.57\%). Results showed that broilers and backyard chicken had been infected by the virus, suggesting the presence of AMPV on the Poultry Production Pole of Bahia.

KEYWORDS: Avian metapneumovirus, backyard chicken, broilers, indirect ELISA. 


\section{INTRODUÇÃO}

O metapneumovírus aviário (AMPV) vem sendo observado com maior frequência no sistema intensivo de produção avícola e se destacando entre os agentes respiratórios de importância para avicultura industrial, causando perdas econômicas significantes (GAMA et al., 2006). É também conhecido como o vírus da rinotraqueíte infecciosa dos perus (TRT) e em galinhas está associado à síndrome da cabeça inchada (SCI) (NAYLOR \& JONES, 1993).

O AMPV pertence à família Paramyxoviridae, subfamília Pneumovirinae, gênero Metapneumovírus (NJENGA et al., 2003). Este vírus tem como hospedeiros naturais perus e galinhas. Contudo, ele também já foi isolado em aves silvestres como patos (TOQUIN et al., 1999), faisões, pombos (GOUGH et al., 1988), galinha d'angola (PICAULT et al., 1987) pardais, gaivotas, gansos, andorinhas (SHIN et al., 2002) e avestruzes (CADMAN et al., 1994).

Os primeiros relatos da presença do AMPV ocorreram em perus e logo subsequentemente em galinhas no final dos anos 70, na África do Sul (BUYS \& DU PREEZ, 1980; BUYS et al., 1989). Posteriormente, em muitos países europeus, no Japão e nos Estados Unidos ocorreram relatos da presença do vírus (DROUIN et al., 1985; WYETH et al., 1987; COOK et al., 1988; HAFEZ, 1993; TANAKA et al., 1995; NAKAMURA et al., 1997; COOK et al., 1999). No Brasil, um estudo sorológico demonstrou a presença de anticorpos contra AMPV nas principais regiões avícolas brasileiras (ARNS et al., 1997). Desde então, a alta prevalência da infecção por este agente em criações de frangos de corte tem sido observada nestas regiões (ARNS, 2006). O diagnóstico sorológico que vem sendo utilizado mais frequentemente nas infecções pelo AMPV é o ensaio imunoenzimático (ELISA) (GRANT et al., 1987).

Em plantéis de frangos de corte o AMPV é frequentemente associado à SCI, que se caracteriza pela presença de um quadro respiratório, inchaço do seio infraorbital e edema submandibular (SILVA et al., 1994). Em reprodutoras e poedeiras comerciais, a enfermidade pode apresentar, além dos sinais respiratórios, sintomatologia nervosa como torcicolo, opistótono e falta de coordenação; e queda na produção e qualidade dos ovos (ARNS et al., 2000; RISTON, 2007). Frequentemente os quadros respiratórios são agravados pela associação do AMPV com infecções secundárias, principalmente por Escherichia coli (VAN DE ZANDE et al., 2001).

Os prejuízos econômicos do AMPV sobre a produção decorrem da piora da conversão alimentar, custo com medicamentos, redução da postura, diminuição do ganho de peso e aumento das taxas de mortalidade e condenação de carcaças (O'BRIEN, 1985; GAMA, et al., 2006). O controle do AMPV é baseado no emprego de medidas de biosseguridade e programas de vacinação nas criações avícolas industriais, além do uso de quimioterápicos no combate às infecções secundárias (ARNS, 2006).

Observando-se a frequência com que frangos de corte manifestam sintomas respiratórios e a possibilidade da ocorrência da SCI na região em estudo, o presente trabalho teve como objetivo determinar a frequência de anticorpos contra o AMPV em criações não vacinadas de frangos de corte e galinhas de quintal no polo avícola do Estado da Bahia.

\section{MATERIAL E MÉTODOS}

As amostras de soro foram obtidas de criações de frangos de corte, não vacinados, oriundas de empresas avícolas e de propriedades com criação de galinhas de quintal, também não vacinadas, localizadas nos municípios de Conceição da Feira, São Gonçalo dos Campos, Feira de Santana, Muritiba, Entre Rios, Santo Antônio de Jesus, Conceição do Coité, Santo Amaro da Purificação, Cícero Dantas, Irará, Governador Mangabeira e Ribeira do Pombal, pertencentes ao polo avícola do Estado da Bahia. Foram analisadas 890 amostras, sendo 622 amostras de frangos de corte de 35 lotes, coletadas no período de maio de 2007 a março de 2009, e 268 amostras de galinhas de quintal em dezessete pequenas propriedades de abril de 2008 a março de 2009. Foram obtidos soros de aves de criação comercial com idade entre 30 E 60 dias de vida e de aves caipiras com idade de quatro meses a três anos.

Coletaram-se as amostras de sangue dos frangos de corte e das galinhas de quintal através da punção da veia braquial das aves e, após a retração do coágulo, os soros foram transferidos para tubos tipo eppendorf devidamente identificados e mantidos congelados a $-20^{\circ} \mathrm{C}$ até o processamento.

Em cada uma das propriedades de criações comerciais e caipiras estudadas foi preenchida uma ficha 
com informações sobre o histórico clínico das aves.

Realizaram-se as análises dos soros no Laboratório de Sanidade Avícola da Bahia (LASAB) da Escola de Medicina Veterinária (EMEV) da Universidade Federal da Bahia (UFBA).

Os soros foram testados utilizando o teste de imunoadsorção enzimática (ELISA indireto), através do kit comercial FlockChek* APV (Lab. IDEXX (C) para a avaliação e monitoramento da resposta humoral a partir da detecção de anticorpos contra o AMPV. Procedeu-se à execução e interpretação dos testes de acordo com as recomendações do fabricante.

Os resultados foram calculados e interpretados através do programa $\mathrm{xChek}{ }^{\circledR}$, em que as densidades ópticas (DO) de cada uma das amostras são relacionadas com os controles positivos e negativos da placa utilizada, gerando um índice denominado razão $\mathrm{S} / \mathrm{P}$ (sample/positive). A razão $\mathrm{S} / \mathrm{P}$ determina o ponto de corte, ou seja, o valor de densidade óptica no teste que determina os soros positivos e negativos. A soropositividade é estabelecida através de um limite de titulação, sendo considerados positivos títulos acima de 396 (OWOADE et al., 2006).

Realizou-se a análise estatística do estudo por meio do programa SPSS 12.0. Os dados foram anali- sados por meio do teste t de Student. Para o cálculo, considerou-se o intervalo de confiança de $95 \%$.

\section{RESULTADOS}

No presente trabalho, foram encontrados anticorpos contra o metapneumovírus aviário em 144 frangos de corte e 187 galinhas de quintal, ambos os grupos não vacinados. Observou-se um maior percentual de aves soropositivas em criações de galinhas de quintal $(69,78 \%)$ em relação aos frangos de corte $(23,15 \%), p=0,1$ (Tabela 1$)$.

Como observado na Tabela 1, foram obtidos nos dois grupos do estudo elevados coeficientes de variação $(\mathrm{CV})$, sugerindo que não houve uniformidade da resposta imunológica dessas aves diante dos possíveis desafios de campo pelo AMPV. Ainda assim, o $\mathrm{CV}$ do grupo de galinhas de quintal foi menor do que o de frangos de corte, o que demonstra uma maior homogeneidade no primeiro grupo.

Os lotes do grupo de frangos de corte tiveram uma frequência de anticorpos contra o metapneumovírus aviário $(77,14 \%)$ menor do que as propriedades de aves caipiras $(94,12 \%)$ e ambos os grupos apresentaram uma ou mais amostras de soro positiva (Tabela 2).

TABELA1. Frequência de anticorpos, valores de titulação, coeficiente de variação e desvio-padrão pela infecção pelo metapneumovírus aviário em aves de criações de frangos de corte e de galinhas de quintal no polo avícola da Bahia

\begin{tabular}{lcccccc}
\hline Grupos & $\mathrm{N}^{\mathrm{o}}$ de aves & $\begin{array}{c}\mathrm{N}^{\mathrm{o}} \text { de aves positivas } \\
(\%)\end{array}$ & $\begin{array}{c}\mathrm{N}^{\mathrm{o}} \text { de aves negativos } \\
(\%)\end{array}$ & $\begin{array}{c}\text { Títulos } \\
\text { mín. e máx. }\end{array}$ & $\mathrm{CV}$ & $\mathrm{SD}$ \\
\hline Frangos de corte & 622 & $144(23,15)$ & $478(76,85)$ & $1-18814$ & 281,19 & 2311,52 \\
Galinhas de quintal & 268 & $187(69,78)$ & $81(30,22)$ & $1-27196$ & 131,85 & 4884,42 \\
\hline
\end{tabular}

$\mathrm{p}=0,1$

TABELA 2. Frequência de anticorpos contra o metapneumovírus aviário em lotes de frangos de corte e propriedades de galinhas de quintal no polo avícola da Bahia

\begin{tabular}{lccc}
\hline Grupos & $\mathrm{N}^{\mathrm{o}}$ de lotes - propriedades & $\mathrm{N}^{\mathrm{o}}$ de lotes - propriedades & Frequência \\
\hline Frangos de corte & & positivas * & $(\%)$ \\
Galinhas de quintal & 35 & 27 & 77,14 \\
\hline
\end{tabular}

* Presença de uma ou mais aves soropositivas 
No grupo de criação industrial foram identificados anticorpos contra o AMPV em $66,67 \%$ e $33,33 \%$ das aves com e sem relatos de sintomas respiratórios, respectivamente. Nas cirações de galinhas de quintal também foram observadas freqüências de títulos tanto nas aves que apresentavam os sintomas respiratórios $(60,43 \%)$ quanto naquelas com ausência destes sintomas $(39,57 \%)$ (Figura 1$)$.

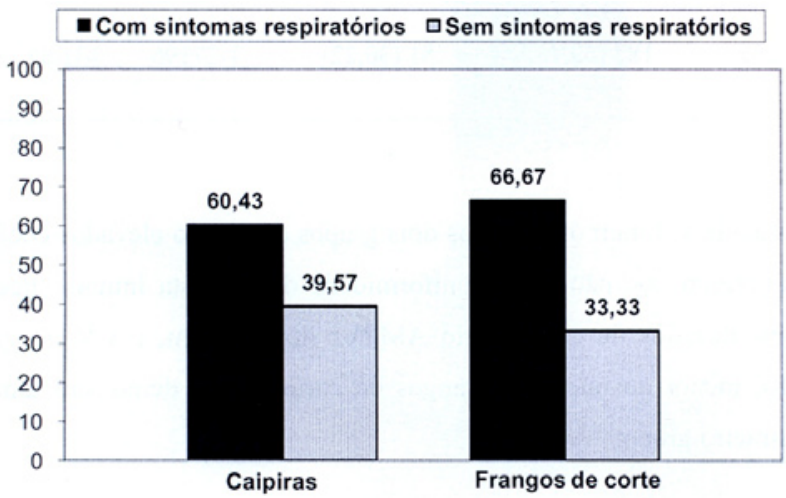

FIGURA 1. Análise das amostras de soro na infecção pelo metapneumovírus aviário em frangos de corte e galinhas de quintal no polo avícola da Bahia, em relação à presença e ausência de sintomas respiratórios, por percentual.

\section{DISCUSSÃO}

Não existe no Estado da Bahia até o momento um estudo soroepidemiológico a respeito da presença de anticorpos contra o AMPV, embora a alta prevalência da infecção por este agente em criações de frangos de corte já tenha sido observada nas principais regiões avícolas brasileiras (ARNS, 2006).

Os resultados obtidos neste estudo demonstraram que a infecção pelo metapneumovírus aviário está presente nas criações, não vacinadas, industriais e de galinhas de quintal no polo avícola da Bahia, com uma maior frequência nas criações caipiras do que nas criações de frangos de corte. Este fato pode ser atribuído à diferença na faixa de idade das aves nos grupos estudados, observando-se que as aves caipiras permanecem por mais tempo em contato com o vírus a campo. O emprego de medidas de biosseguridade, as boas condições de higiene e as práticas de manejo que fazem parte da rotina das criações comerciais devem contribuir para esse resultado (AL-ANKARI et al., 2004). Já nas criações de aves de fundo de quintal, a ausência de um controle sanitário eficiente é resultante da falta de manejo efetivo da criação, da incorporação de aves de condição sanitária desconhecida, das condições precárias de higiene e limpeza dos abrigos, do sistema de criação semiextensivo das aves, e da presença de aves de diferentes idades numa mesma criação, aliada à falta de atenção oficial para esse segmento (SALES et al., 2007).

A presença de frangos de corte soropositivos é de $23,15 \%$ na região estudada, o que está de acordo com dados obtidos na Inglaterra (COOK et al., 1988) e com o estudo realizado por PERES et al. (2006) no Estado de Mato Grosso do Sul, onde foram encontrados $18,3 \%$ de amostras positivas em frangos de corte. ARNS et al., (1997) demonstraram títulos positivos para a infecção pelo AMPV em 63\% das criações, não vacinadas, de frangos de corte, matrizes pesadas e poedeiras comerciais, pertencentes aos estados de Pernambuco, Minas Gerais, São Paulo, Paraná, Santa Catarina e Rio Grande do Sul, através da técnica de Elisa para o AMPV.

Já o percentual dos lotes comerciais soropositivos é considerado elevado (77,14\%), demonstrando a presença de uma ou mais aves sororreagentes para o vírus. PERES et al. (2006) identificaram lotes com 90,7\% de títulos positivos ou suspeitos para o AMPV. Em contrapartida, OWOADE et al. (2006), em estudo realizado na Nigéria, identificaram somente $30 \%$ de lotes de frangos de corte soropositivos.

Os dados do presente estudo diferem dos resultados de DROUAL \& WOOLCOCK (1994), TORO et al. (1998) e BOARO et al. (2004), que relataram a ausência de anticorpos contra AMPV em plantéis de frangos de corte na região Central da Califórnia, na região Central do Chile e na região do Planalto Médio no Estado do Rio Grande do Sul, respectivamente.

Logo, na tentativa de eliminar ou reduzir os riscos de infecção pelo AMPV nos plantéis de frangos de corte no polo avícola da Bahia, um controle sanitário efetivo para a presença do agente a campo deve ser implantando, através do emprego de medidas que melhorem as condições de ambiência, e promovam a limpeza e desinfecção das instalações e a realização do vazio sanitário nestes plantéis avícolas (COOK, 2000; GOYAL et al., 2003).

Identificaram-se neste trabalho altos percentuais de títulos individuais $(69,78 \%)$ e propriedades de gali- 
nhas de quintal soropositivas $(94,12 \%)$ para o AMPV no polo avícola da Bahia. Resultados semelhantes foram encontrados em estudo realizado na Nigéria por OWOADE et al. (2006), identificando-se elevados níveis de anticorpos contra o AMPV em cerca de $70 \%$ de aves caipiras, não vacinadas, e em $65 \%$ das criações destas aves na Nigéria.

A elevada frequência de anticorpos em galinhas de quintal contra o AMPV evidenciada neste estudo confirma a hipótese de que estas aves foram infectadas pelo vírus, servindo como reservatório, podendo também ser utilizadas como sentinelas em determinadas localidades, possibilitando, dessa maneira, o acompanhamento soroepidemiológico da circulação do vírus a campo. Programas educacionais para informar os criadores de aves de quintal sobre noções adequadas de criação e manejo para melhorar a condição sanitária destas criações são de grande importância no meio rural. Além de favorecerem o controle do vírus, eles reduzem o risco da manutenção de agente no ambiente (ALBINO et al., 2005).

COOK et al. (1988) afirmaram que é possível encontrar anticorpos contra o AMPV em aves aparentemente saudáveis. Esta hipótese foi confirmada neste trabalho, que identificou títulos de anticorpos contra o AMPV nas aves de criações industriais e caipiras aparentemente saudáveis. Entretanto, identificaram-se também aves com sinais respiratórios soropositivas para o vírus, corroborando os dados obtidos por PERES et al. (2006) e SILVA et al., (1994).

Este estudo relata pela primeira vez a evidência sorológica do AMPV no polo avícola da Bahia em criações, não vacinadas, de frangos de corte e galinhas de quintal. Os resultados apresentados neste trabalho reforçam a necessidade do conhecimento sobre a epidemiológica do AMPV na região estudada, através da realização de pesquisas para a identificação da amostra circulante do AMPV a campo, por meio do isolamento e caracterização viral.

\section{CONCLUSÃO}

Verificou-se a infecção pelo metapneumovírus aviário nas criações, não vacinadas, de frangos de corte e galinhas de quintal no polo avícola da Bahia. A avaliação sorológica das criações comerciais e caipiras revelou a presença de anticorpos contra o vírus em ambos os grupos estudados, independente do sistema de criação e das condições sanitárias.

\section{REFERÊNCIAS}

AL-ANKARI, A. R. S.; AL-RAMADAN M. A; EL-DEMERDASH, M. M. Risk factors associated with prevalence of swollen head syndrome (SHS) in broiler chickens in Eastern Province Saudi Arabia. International Journal of Poultry Science, v. 3, n. 10, p. 646-650, 2004.

ALBINO, L. F. T.; NERY, L. R.; VARGAS JÚNIOR, J. G.; SILVA, J. H. V. Biossegurança. In: ___ criação de frango e galinha caipira: avicultura alternativa. Viçosa: Aprenda Fácil, 2005. p. 159-166.

ARNS, C. W.; CASTRO, T. A. M. G.; PERREIRA, V. R.; COSWIG, L. T. Situation of avian pneumovirus in Brazil, Virus Reviews and Research, v. 2, n. 1, p. 101-102, 1997.

ARNS, C. W.; COSWIG, L. T.; MONTEIRO, M. C. G. B. Pneumovirose aviária. In: BERCHIERI JR, A.; MACARI, M. Doença das aves. Campinas: Facta, 2000. p. 359-363.

ARNS, C. W. Pneumovírus aviário. In: ANDREATTI FILHO, R. L. Saúde aviária e doenças. São Paulo: Roca, 2006. v. 1, p. 216-222.

BOARO, L.; KRETZ, L. C.; POLETTO, R.; UONFRUHAUF, M. Ausência de anticorpo contra o vírus da cabeça inchada em frangos de corte no Planalto Médio do Rio Grande do Sul, Brasil. Ciência Rural, v. 34, n. 1, p. 285-287, 2004.

BUYS, S. B.; DU PREEZ, J. H. A preliminary report on the isolation of virus causing sinusitis in turkeys in South Africa and attempts to attenuate the virus. Turkeys, v. 28, p. 36-46. 1980.

BUYS, S. B.; DU PREEZ, J. H.; ELS, H. J. Swollen head syndrome in chickens: a preliminary report on the isolation of a possible aetiological agent. Journal of the South African Veterinary Association, v. 60, p. 221-222, 1989.

CADMAN, H. F.; KELLY, P. J.; ZHOU, R.; DAVELAAR, F.; MASON, P. R. A serosurvey using enzyme-linked immunosorbent assay for antibodies against poultry pathogens in ostriches (Struthio camelus) from Zimbabwe. Avian Diseases, v. 38, p. 621-625, 1994.

COOK, J. K. A.; DOLBY, C. A.; SOUTHEE, D. J.; MOCKETT, A. P. A. Demonstration of antibodies to turkey rhinotracheitis virus in serum from commercially reared flocks of chickens. Avian Pathology, v. 17, p. 403-410, 1988.

COOK, J. K. A.; HUGGIES, M. B.; ORBELL, S. J.; SENNE, D. A. Preliminary antigenic characterization of an avian pneumovirus isolated from commercial turkeys in Colorado, USA. Avian Pathology, v. 28, p. 607-617, 1999.

COOK, J.K.A. Avian Pneumovirus Infections of Turkeys and Chickens. The Veterinary Journal, v.160, p.118-125, 2000. 
DROUAL, R.; WOOLCOCK, P. R. Swollen head syndrome associated with $E$. coli and infectious bronchitis virus in the Central Valley of California. Avian Pathology, v. 23, p. 733-742, 1994.

DROUIN, P.; TOUX, J. Y.; PICAULT, J. P. Le syndrome infectieux de la grosse tête chez l'espece poule. L'Aviculteur, v. 460, p. 93-96, 1985.

GAMA, N. M. S. Q.; INOUE, A. Y.; BUIM, M. R.; GUASTALLI, E. A. L. Doenças respiratórias. Guia da Avicultura Industrial, n. 6, ed. 1146, p. 24-28, 2006.

GOUGH, R. E.; COLLINS, M. S.; COX, W. J.; CHETTLE, N. J. Experimental infection of turkeys, chickens, ducks, geese, guinea fowl, pheasants and pigeons with turkey rhinotracheitis virus. Veterinary Record, v. 123, p. 58-59, 1988.

GOYAL, S.M.; LAUER, D.; FRIENDSHUH, K.; HALVORSON, D.A. Seroprevalence of Avian Pneumovirus in Minnesota Turkeys. Avian Diseases, v.47, p.700-706, 2003.

GRANT, M.; BAXTER-JONES, C.; WILDING, G. P. An enzymelinked immunosorbent assay for the serodiagnosis of turkey rhinotracheitis infection. Veterinary Record, v. 120, p. 279-280, 1987.

HAFEZ, H. M. The role of pneumovirus in the swollen head syndrome of chickens: review. Archivrr Gefluegelkunde, v. 57, p. 181-185, 1993.

NAKAMURA, K.; MASE, M.; TANIMURA, N.; YAMAGUCHI, S.; NAKAZAWA, M.; YUASA, N. Swollen head syndrome in broiler chickens in Japan: Its pathology, microbiology and biochemistry. Avian Pathology, v.26, n.1, p.139 -154, 1997.

NAYLOR, C.J.; JONES, R.C. Turkey rhinotracheitis: a review. Veterinary Bulletin, v.63, p.439-449, 1993.

NJENGA, M. K.; LWAMBA, H. M.; SEAL, B. S. Metapneumoviruses in birds and humans. Virus Research, v. 91, n. 2, p. 163-169, 2003.

O'BRIEN, J.D. Swollen head syndrome in broiler breeders. Veterinary Record, v.117, n.23, p.619-620, 1985.

OWOADE, A. A.; DUCATEZ, M. F.; MULLER, C. P. Seroprevalence of avian influenza virus, infectious bronchitis virus, reovirus, avian pneumovirus, infectious laryngotracheitis virus, and avian leukosis virus in nigerian poultry. Avian Diseases, v. 50, p. 222-227, 2006.

PERES, M. F.; CARRIJO, A. S.; HIGA, J. A.; DE OLIVEIRA, J. M. Evidência sorológica de pneumovírus aviário em lotes de frangos de corte em municípios de Mato Grosso do Sul. Pesquisa Veterinária Brasileira, v. 26, n. 4, 2006.

PICAULT, J. P.; GIRAUD, P.; DROVIN, P.; GUITTET, M.; BENNEJEAN, G.; LAMANDE, J.; TOQUIN, D.; GUEGUEN, C. Isolation of a TRTV-like virus from chickens with swollen head syndrome. Veterinary Record, v. 121, p. 135, 1987.

RISTOW, L. E. Pneumovírus aviário: importância, epidemiologia e diagnóstico. Revista Aveworld, n. 27, p. 80-83, 2007.

SALES, T. S.; HERVAL, E. F. G.; CÉSAR, A. E. R.; RAMOS, I.; BATINGA, T. B.; SILVA, P. S.; MAIA, P. C. C.; FERNANDES, L. Títulos de anticorpos contra o vírus da doença de Newcastle em três diferentes sistemas de criação avícola na região de Feira de Santana - Bahia. Revista Brasileira de Saúde e Produção Animal, v. 8, n. 4, p. 386-393, 2007.

SHIN, H. J.; NAGARAJA, K.V.; McCOMB, B.; HALVORSON, D. A.; JIRJIS, F.F.; SHAW, D. P.; SEAL, B. S.; NJENGA, M. K. Isolation of avian pneumovirus from mallard ducks that is genetically similar to viruses isolated from neighboring commercial turkeys. Virus Research, v. 83, p. 207-212, 2002.

SILVA, E. N.; ARNS, C. W.; SILVA, J. M. L. Observações sobre a síndrome da cabeça inchada em matrizes pesadas no Brasil. Arquivo Brasileiro de Medicina Veterinária e Zootecnia, v. 46, n. 3, p. 210-222, 1994.

TANAKA, M.; TAKUMA, H.; KOKUMAI, N.; OISHI, E.; OBI, T.; HIRAMATSU, K.; SHIMIZU, Y. Turkey rhinotracheitis virus isolated from broiler chickens with swollen head syndrome in Japan. Journal of Veterinary Medical Science, v. 57, p. 939941, 1995.

TOQUIN, D.; BAYON-AUBOYER, M. H.; ETERRADOSSI, N.; JESTIN, V. Isolation of a pneumovirus from a Muscovy duck. Veterinary Record, v. 145, p. 680, 1999.

TORO, H.; HIDALGO, M.; IBANEZ, M.; HAFEZ, M. Serologic evidence of pneumovirus in Chile. Avian Diseases, v. 42, p. 815$817,1998$.

VAN DE ZANDE, S.; NAUWYNCK, H.; PENSAERT, M. The clinical, pathological and microbiological outcome of Escherichia coli $\mathrm{O} 2: \mathrm{K} 1$ infectious in avian pneumovirus infected turkeys. Veterinary Microbiology, v. 81, p. 353-365, 2001.

WYETH, P. I.; CHETTLE, R. E.; COLLINS, M. S. Antibodies to TRT in chickens with swollen head syndrome. Veterinary Record, v. 120 , p. 286-287, 1987. 